Journal of Mathematics and Statistics 5 (3):159-166, 2009

ISSN 1549-3644

(C) 2009 Science Publications

\title{
Exact Solutions of Mass Transfer over a Stretching Surface with Chemical Reaction and Suction/Injection
}

\author{
Hassan A.M. El-Arabawy \\ Department of Mathematics, Faculty of Science, Ain Shams University, Cairo Egypt
}

\begin{abstract}
Problem statement: In this research the researchers studied and made an analysis to the effects of suction/injection and chemical reaction on mass transfer characteristics over a stretching surface. The researcher studied the effects of some parameters appear on mass transfer. Approach: Transforming the system of partial differential equations to a system of ordinary differential equations and obtaining the exact analytical solution for the momentum boundary layer problem and the concentration boundary layer equation. Results: The effects of varying the suction and injection, chemical reaction parameter, L, Schmidt number, Sc and concentration parameter $\gamma$ were determined. Conclusion: The exact analytical solution was obtained in the presence of the extra parameters, suction/ injection parameter and the chemical reaction parameter.
\end{abstract}

Key words: Chemical reaction, stretching surfaces, mass transfer, suction and injection

\section{INTRODUCTION}

The mass and momentum transport in laminar boundary layer on moving, stationary and linearly stretching surface has important applications in polymer industry $^{[1,2]}$ and electrochemistry ${ }^{[3,4]}$. However, there are fluids which react chemically with some other ingredients present in them. Das, Deka and Soundalgekar ${ }^{[5]}$ have studied the effect of a chemical reaction on the flow past an impulsively started infinite vertical plate with uniform heat flux. Anderson, Hansen and Holmedal ${ }^{[6]}$ have studied the diffusion of a chemical reactive species from a linear stretching sheet. Anjalidevi and Kandasamy ${ }^{[7]}$ have examined the effect of a chemical reaction on the flow along a semi infinite horizontal plate in the presence of heat transfer. Anjalidevi and Kandasamy ${ }^{[8]}$ have analyzed the effect of a chemical reaction on the flow in the presence of heat transfer and magnetic field. Muthucumaraswamy and Ganesan ${ }^{[9]}$ have investigated the effect of a chemical reaction on the unsteady flow past an impulsively started semi-infinite vertical plate which is subjected to uniform heat flux. Muthucumaraswamy and Ganesan ${ }^{[10]}$ have analyzed the effect of a chemical reaction on the unsteady flow past an impulsively started vertical plate which is subjected to uniform mass flux. And in the presence of heat transfer. Muthucumaraswamy ${ }^{[11]}$ has studied the effects of suction on heat and mass transfer along a moving vertical surface in the presence of a chemical reaction.

The purpose of this investigation is to study the effects of suction/ injection and chemical reaction on mass transfer over a stretching surface.
Mathematical analysis: Consider a steady, laminar, incompressible and viscous fluid on a continuous stretching surface with mass transfer, chemical reaction and suctionlinjection. The fluid properties are assumed to be constant in a limited temperature range. The concentration of diffusing species is very small in comparison to other chemical species, the concentration of species far from the surface, $\mathrm{C} \infty$ is infinitesimally very small ${ }^{[12]}$. The chemical reactions are taking place in the flow and all physical properties are assumed to be constant. The $\mathrm{x}$-axis runs along the continuous surface in the direction of the motion and the y-axis is perpendicular to it. The basic boundary layer equations for the steady flow of Boussinesq type of fluid are as follows:

$\frac{\partial u}{\partial x}+\frac{\partial v}{\partial y}=0$

$u \frac{\partial u}{\partial x}+v \frac{\partial u}{\partial y}=v \frac{\partial^{2} u}{\partial y^{2}}$

$\mathrm{u} \frac{\partial \mathrm{C}}{\partial \mathrm{x}}+\mathrm{v} \frac{\partial \mathrm{C}}{\partial \mathrm{y}}=\mathrm{D} \frac{\partial^{2} \mathrm{C}}{\partial \mathrm{y}^{2}}-\mathrm{k}_{1} \mathrm{C}$

Where:

$\mathrm{u}, \mathrm{v}=$ The velocity components along $\mathrm{x}, \mathrm{y}$ coordinates respectively

$v \quad=$ The viscosity of the cooling fluid

$\mathrm{C}=$ Concentration of the fluid

$\mathrm{D}=$ The effective diffusion coefficient 
The constant $\mathrm{k}_{1}$ is the first order chemical reaction rate (when $\mathrm{k}_{1}<0$ generating reactant and $\mathrm{k}_{1}>0$ destructive reactant). are:

The boundary conditions for the present problem

$$
\left.\begin{array}{l}
y=0: u=U_{0} x, v=v_{w}, C=C_{w} \\
y \rightarrow \infty: u \rightarrow 0, C \rightarrow C_{\infty},
\end{array}\right\}
$$

Where:

$\mathrm{U}_{0}=\mathrm{A}$ constant called stretching rate

$\mathrm{v}_{\mathrm{w}}=$ A non-zero velocity component at the wall

$\mathrm{C}_{\mathrm{w}}=$ The concentration of the reactant at surface

The suitable similarity variables, for the problem under consideration, are:

$$
\begin{aligned}
& \eta=\sqrt{\frac{\mathrm{U}_{0}}{v}} \mathrm{y}, \Psi(\mathrm{x}, \mathrm{y})=\sqrt{\nu \mathrm{U}_{0}} \mathrm{xf}(\eta) \\
& \mathrm{C}=\mathrm{C}_{\infty}+\mathrm{c} \mathrm{x}^{\gamma} \phi(\eta)
\end{aligned}
$$

where, the stream function $\Psi(\mathrm{x}, \mathrm{y})$ is defined in the usual way:

$$
\mathrm{u}=\frac{\partial \Psi}{\partial \mathrm{y}}, \quad \mathrm{v}=-\frac{\partial \Psi}{\partial \mathrm{x}}
$$

Where:

$$
\begin{aligned}
& \text { c } \quad=\text { Constant } \\
& \gamma=\text { The concentration parameter } \\
& \eta \quad=\text { The similarity variable } \\
& \mathrm{f} \text { and } \phi=\text { The dimensionless stream function and }
\end{aligned}
$$

The wall concentration on the stretching surface $\mathrm{C}_{\mathrm{w}}$ is:

$$
\mathrm{C}(\mathrm{x}, \mathrm{y}=0)-\mathrm{C}_{\infty}=\mathrm{C}_{\mathrm{w}}-\mathrm{C}_{\infty}=\mathrm{c} \mathrm{x}^{\gamma_{1}} \phi(0)
$$

Then, Eq. 2 and 3 reduce to the following system of nonlinear ordinary differential equations:

$$
\begin{aligned}
& f^{\prime \prime \prime}+f f^{\prime \prime}-\left(f^{\prime}\right)^{2}=0 \\
& \phi^{\prime \prime}-L \phi+\operatorname{Sc}\left(f \phi^{\prime}-\gamma_{1} f^{\prime} \phi\right)=0
\end{aligned}
$$

In the above equations a prime denotes differentiation with respect to $\eta$, where:

$\mathrm{L}=\frac{\mathrm{k}_{1} \mathrm{Sc}}{\mathrm{U}_{0}}$ (chemical reaction parameter)

$\mathrm{Sc}=\frac{\mathrm{v}}{\mathrm{D}}($ Schmidt number $)$
The transformed boundary conditions are given by:

$$
\left.\begin{array}{l}
\eta=0: f(0)=-\frac{v_{w}}{\sqrt{v U_{0}}}=f_{w}, \quad f^{\prime}(0)=1, \phi(0)=1 \\
\eta \rightarrow \infty: f^{\prime}(\infty)=0, \phi(\infty)=0
\end{array}\right\}
$$

Note that, $\mathrm{f}_{\mathrm{w}}<0$ corresponds to injection, $\mathrm{f}_{\mathrm{w}}<0$ corresponds to suction and $f_{w}=0$ is the case when the surface is impermeable.

\section{MATERIALS AND METHODS}

\section{Exact solution:}

Exact solution of the momentum boundary layer problem: Now let us seek a solution of non-linear differential Eq. 8 in the form:

$f(\eta)=f_{w}+\frac{1-e^{-\alpha \eta}}{\alpha},(\alpha>0)$

Which is satisfied by the following boundary conditions:

$\left.\begin{array}{l}\eta=0: f(0)=f_{w}, \\ \eta \rightarrow \infty: f^{\prime}(\infty)=0\end{array}\right\}$

On substituting (11) into (8) and using boundary conditions (12) we get:

$$
\alpha=\frac{\mathrm{f}_{\mathrm{w}}+\sqrt{\mathrm{f}_{\mathrm{w}}^{2}+4}}{2}
$$

Therefore, the velocity components takes the form:

$$
\mathrm{u}=\mathrm{U}_{0} \mathrm{x}\left(\mathrm{f}_{\mathrm{w}}+\frac{1-\mathrm{e}^{-\alpha \eta}}{\alpha}\right)
$$

And:

$\mathrm{v}=-\sqrt{\nu \mathrm{U}_{0}}\left(\mathrm{f}_{\mathrm{w}}+\frac{1-\mathrm{e}^{-\alpha \eta}}{\alpha}\right)$

Thus, from (11), we get a simple exact analytical solution of the boundary value problem (8) with boundary conditions (12). This form of solution was first obtained by Gupta and Gupta ${ }^{[13]}$ Andersson $^{[14]}$ and recently, Cortell ${ }^{[15]}$.

Exact solution of the concentration boundary layer equation: The ordinary differential equation (9) with Eq. 11, we get the following ordinary differential equation: 


$$
\phi^{\prime \prime}+\operatorname{Sc}\left(\mathrm{f}_{\mathrm{w}}+\frac{1-\mathrm{e}^{-\alpha \eta}}{\alpha}\right) \phi^{\prime}-\left(\operatorname{Sc} \gamma \mathrm{e}^{-\alpha \eta}+\mathrm{L}\right) \phi=0
$$

With boundary conditions are given by:

$$
\phi(0)=1, \phi(\infty)=0
$$

Equation 15 is an homogenous linear ordinary differential of second order with variable coefficients. Now to seek the solution of boundary value problem (15): (16) we introduce the change of variable:

$\frac{\mathrm{Sc}}{\alpha^{2}} \mathrm{e}^{-\alpha \eta}=\xi$

Then Eq. 15 is written as:

$\xi \phi^{\prime \prime}+\left[1-\left(\alpha f_{w}+1\right) \frac{S c}{\alpha^{2}}+\xi\right] \phi^{\prime}-\left(\gamma+\frac{L}{\alpha^{2}} \xi^{-1}\right) \phi=0$

With the boundary conditions:

$\phi\left(\xi=\frac{\mathrm{Sc}}{\alpha^{2}}\right)=1 \quad$ and $\quad \phi(\infty)=0$

Equation 18 is similar to Kummer's differential equation which has a Kummer confluent hypergeometric function ${ }_{1} \mathrm{~F}_{1}$ as solution. Therefore, the solution of Eq. 18 satisfying (19) in terms of Kummer confluent hypergeometric function ${ }_{1} \mathrm{~F}_{1}$ is given by:

$\phi(\xi)=\left(\frac{\alpha^{2}}{\mathrm{Sc}} \xi\right)^{\left(\kappa_{1}+\kappa_{2}\right)} \frac{{ }_{1} \mathrm{~F}_{1}\left(\kappa_{1}+\kappa_{2}-\gamma ; 1+2 \kappa_{2} ;-\xi\right)}{{ }_{1} \mathrm{~F}_{1}\left(\kappa_{1}+\kappa_{2}-\gamma ; 1+2 \kappa_{2} ;-\frac{\mathrm{Sc}}{\alpha^{2}}\right)}$

Where:

$\kappa_{1}=\frac{\mathrm{Sc}}{2 \alpha^{2}}\left(1+\alpha \mathrm{f}_{\mathrm{w}}\right)$

$\kappa_{2}=\frac{\sqrt{4 L \alpha^{2}+\mathrm{Sc}^{2}\left(1+\alpha f_{w}\right)^{2}}}{2 \alpha^{2}}$

The solution of (20) in terms of $\eta$ is written as:

$\phi(\eta)=\mathrm{e}^{-\left(\kappa_{1}+\kappa_{2}\right) \alpha \eta} \frac{{ }_{1} \mathrm{~F}_{1}\left(\kappa_{1}+\kappa_{2}-\gamma ; 1+2 \kappa_{2} ;-\frac{S c}{\alpha^{2}} \mathrm{e}^{-\alpha \eta}\right)}{{ }_{1} \mathrm{~F}_{1}\left(\kappa_{1}+\kappa_{2}-\gamma ; 1+2 \kappa_{2} ;-\frac{S c}{\alpha^{2}}\right)}$

On the other hand, the local surface mass flux, with Eq. 21, can be expressed as:

$$
\begin{aligned}
\mathrm{M}_{\mathrm{w}} & =-\mathrm{D}\left(\frac{\partial \mathrm{C}}{\partial \mathrm{y}}\right)_{\mathrm{y}=0} \\
& =-\mathrm{Ddx} \mathrm{x}^{\gamma} \varphi^{\prime}(0) \sqrt{\frac{\mathrm{U}_{0}}{\mathrm{v}}} \\
& =-\mathrm{Ddx} \mathrm{x}^{\gamma} \sqrt{\frac{\mathrm{U}_{0}}{\mathrm{v}}} \\
& \left(\begin{array}{l}
\frac{-\alpha\left(\kappa_{1}+\kappa_{2}\right)+}{\alpha c\left(\kappa_{1}+\kappa_{2}-\gamma\right)_{1} \mathrm{~F}_{1}\left(1+\kappa_{1}+\kappa_{2}-\gamma ; 2\left(1+\kappa_{2}\right) ;-\frac{\mathrm{Sc}}{\alpha^{2}}\right)} \\
\alpha\left(1+2 \kappa_{2}\right)_{1} \mathrm{~F}_{1}\left(\kappa_{1}+\kappa_{2}-\gamma ; 1+2 \kappa_{2} ;-\frac{\mathrm{Sc}}{\alpha^{2}}\right)
\end{array}\right)
\end{aligned}
$$

\section{RESULTS}

Table 1-3 shows numerical values of concentration surface gradient values for various values of porosity parameter $f_{w}$, chemical reaction parameter $L$ and Schmidt number Sc and concentration parameter $\gamma$.

Table 1: Concentration surface gradient values for various values of porosity parameter $f_{w}$, chemical reaction parameter $L$ and concentration parameter $\gamma$ when Schmidt number Sc $=0.024$

\begin{tabular}{rrrlll}
\hline fw & $\gamma$ & $\mathrm{L}=0$ & $\mathrm{~L}=0.2$ & $\mathrm{~L}=0.8$ & $\mathrm{~L}=1.2$ \\
\hline-1.5 & -3 & -0.14531400 & 0.385313 & 0.850065 & 1.05508 \\
& -2 & -0.08772400 & 0.403177 & 0.860711 & 1.06410 \\
& -1 & -0.03600000 & 0.420707 & 0.871276 & 1.07307 \\
& 0 & 0.01092560 & 0.437917 & 0.881761 & 1.08199 \\
& 1 & 0.05386980 & 0.454822 & 0.892168 & 1.09086 \\
& 2 & 0.09346970 & 0.471732 & 0.902498 & 1.09968 \\
& 3 & 0.13022900 & 0.487762 & 0.912753 & 1.10845 \\
-1 & -3 & -0.10759000 & 0.394832 & 0.857327 & 1.06198 \\
& -2 & -0.06440170 & 0.41190 & 0.867431 & 1.07061 \\
& -1 & -0.02400000 & 0.427298 & 0.877469 & 1.07920 \\
& 0 & 0.01394970 & 0.443166 & 0.887440 & 1.08774 \\
& 1 & 0.04972900 & 0.458802 & 0.897346 & 1.09625 \\
& 2 & 0.08357660 & 0.474213 & 0.907188 & 1.10471 \\
& 3 & 0.11569700 & 0.489407 & 0.916967 & 1.11312 \\
0 & -3 & -0.04858300 & 0.415251 & 0.872805 & 1.07657 \\
& -2 & -0.02400000 & 0.428145 & 0.881490 & 1.08414 \\
& -1 & 0.00000000 & 0.440925 & 0.890135 & 1.09169 \\
& 0 & 0.02344400 & 0.453592 & 0.898740 & 1.09921 \\
& 1 & 0.04635720 & 0.466150 & 0.907307 & 1.10671 \\
& 2 & 0.06876330 & 0.478600 & 0.915835 & 1.11417 \\
& 3 & 0.09068470 & 0.490945 & 0.924325 & 1.12162 \\
1 & -3 & -0.00536370 & 0.435520 & 0.888893 & 1.09175 \\
& -2 & 0.00938400 & 0.445159 & 0.895976 & 1.09808 \\
& -1 & 0.24000000 & 0.454753 & 0.903040 & 1.10440 \\
& 0 & 0.03848670 & 0.464303 & 0.910084 & 1.11070 \\
& 1 & 0.05284640 & 0.473809 & 0.917108 & 1.11699 \\
& 2 & 0.06708120 & 0.483271 & 0.924113 & 1.12326 \\
& 3 & 0.08119340 & 0.492690 & 0.931098 & 1.12951 \\
& -3 & 0.01235530 & 0.444956 & 0.896802 & 1.09930 \\
& -2 & 0.02421220 & 0.453301 & 0.903164 & 1.10504 \\
& -1 & 0.03600000 & 0.461617 & 0.909511 & 1.11078 \\
& 0 & 0.04771960 & 0.469906 & 0.915844 & 1.11651 \\
& 1 & 0.05937170 & 0.478166 & 0.922164 & 1.12222 \\
& 2 & 0.07095710 & 0.486399 & 0.928470 & 1.12793 \\
& 3 & 0.08247650 & 0.494604 & 0.934762 & 1.13362 \\
\hline & & & & &
\end{tabular}


J. Math. \& Stat., 5 (3):159-166, 2009

Table 2: Concentration surface gradient values for various values of porosity parameter $\mathrm{f}_{\mathrm{w}}$, chemical reaction parameter $\mathrm{L}$ and concentration parameter $\gamma_{1}$ when Schmidt number $\mathrm{Sc}=0.7$

\begin{tabular}{rrrrrr}
\hline $\mathrm{f}_{\mathrm{w}}$ & $\gamma_{1}$ & \multicolumn{1}{c}{$\mathrm{L}=0$} & $\mathrm{~L}=0.2$ & $\mathrm{~L}=0.8$ & $\mathrm{~L}=1.2$ \\
\hline-1.5 & -3 & -1.15410 & 2.89785 & -0.64830 & -0.17360 \\
& -2 & 0.22273 & -1.39010 & -0.08070 & 0.21349 \\
& -1 & -1.05000 & -0.23220 & 0.29901 & 0.51508 \\
& 0 & 0.04974 & 0.24455 & 0.59303 & 0.76673 \\
& 1 & 0.45312 & 0.56966 & 0.83831 & 0.98560 \\
& 2 & 0.74032 & 0.82822 & 1.05193 & 1.18118 \\
& 3 & 0.97574 & 1.04858 & 1.24319 & 1.35929 \\
-1 & -3 & 0.30881 & -6.67180 & -0.43610 & -0.00640 \\
& -2 & 7.84013 & -0.97770 & 0.06266 & 0.35400 \\
& -1 & -0.70000 & -0.11640 & 0.42367 & 0.64503 \\
& 0 & 0.12818 & 0.34268 & 0.71195 & 0.89217 \\
& 1 & 0.53880 & 0.66946 & 0.95568 & 1.10912 \\
& 2 & 0.83479 & 0.93167 & 1.16929 & 1.30401 \\
& 3 & 1.07639 & 1.15539 & 1.36112 & 1.48201 \\
0 & -3 & -2.15390 & -0.80900 & 0.15568 & 0.47217 \\
& -2 & -0.70000 & -0.14880 & 0.49415 & 0.74900 \\
& -1 & 0.00000 & 0.30572 & 0.77917 & 0.99205 \\
& 0 & 0.45392 & 0.65419 & 1.02673 & 1.20961 \\
& 1 & 0.79366 & 0.93955 & 1.24670 & 1.40731 \\
& 2 & 1.06932 & 1.18355 & 1.44559 & 1.58912 \\
& 3 & 1.30439 & 1.39849 & 1.62785 & 1.75793 \\
1 & -3 & 0.04585 & 0.31786 & 0.82189 & 1.05589 \\
& -2 & 0.39802 & 0.61595 & 1.04672 & 1.25579 \\
& -1 & 0.70000 & 0.87929 & 1.25353 & 1.44216 \\
& 0 & 0.96472 & 1.11553 & 1.44526 & 1.61690 \\
& 1 & 1.20087 & 1.33016 & 1.62421 & 1.78158 \\
& 2 & 1.41455 & 1.52720 & 1.79220 & 1.93747 \\
& 3 & 1.61015 & 1.70967 & 1.95071 & 2.08562 \\
1.5 & -3 & 0.56913 & 0.75590 & 1.16002 & 1.36476 \\
& -2 & 0.82049 & 0.98358 & 1.34707 & 1.53559 \\
& -1 & 1.05000 & 1.19393 & 1.52334 & 1.69782 \\
& 0 & 1.26133 & 1.38956 & 1.69012 & 1.85236 \\
& 1 & 1.45734 & 1.57257 & 1.84849 & 2.00000 \\
& 2 & 1.64030 & 1.74465 & 1.99937 & 2.14141 \\
& 3 & 1.81203 & 1.90718 & 2.14354 & 2.27719 \\
\hline & & & & &
\end{tabular}

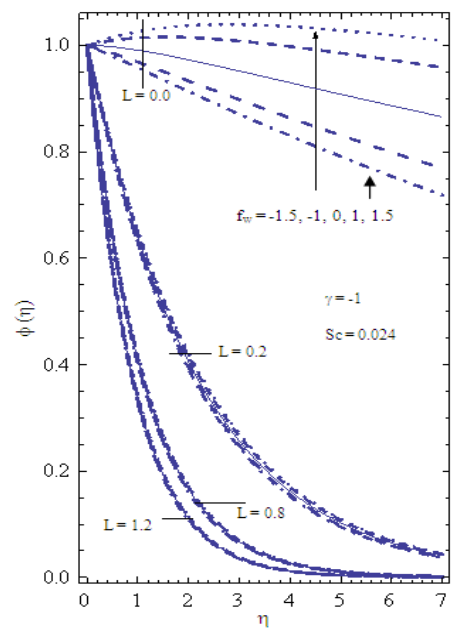

Fig. 1: Concentration profiles for various values of chemical reaction parameter $\mathrm{L}$ and mass transfer $\mathrm{f}_{\mathrm{w}}$

The influence of the mass transfer and chemical reaction parameters on dimensionless concentration are shown in Fig. 1-10, respectively, with various values of concentration parameter $\gamma$ and Schmidt number.
Table 3: Concentration surface gradient values for various values of porosity parameter $f_{w}$, chemical reaction parameter $L$ and concentration parameter $\gamma_{1}$ when Schmidt number Sc $=7$

\begin{tabular}{|c|c|c|c|c|c|}
\hline $\mathrm{f}_{\mathrm{w}}$ & $\gamma_{1}$ & $\mathrm{~L}=0$ & $\mathrm{~L}=0.2$ & $\mathrm{~L}=0.8$ & $\mathrm{~L}=1.2$ \\
\hline \multirow[t]{7}{*}{-1.5} & -3 & -8.98864 & -3.679300 & -2.8097100 & -2.560860 \\
\hline & -2 & -9.80000 & -1.738750 & -1.5530400 & -1.475560 \\
\hline & -1 & -10.50000 & -0.717885 & -0.6420630 & -0.593848 \\
\hline & 0 & 7E-060 & 0.020455 & 0.0811529 & 0.121137 \\
\hline & 1 & 0.63636 & 0.654259 & 0.7075600 & 0.742781 \\
\hline & 2 & 1.20599 & 1.222140 & 1.2703200 & 1.302220 \\
\hline & 3 & 1.72717 & 1.742020 & 1.7863500 & 1.815740 \\
\hline \multirow[t]{5}{*}{-1} & -3 & -4.29080 & -3.683490 & -2.1405100 & -0.867060 \\
\hline & -2 & -5.90320 & -4.444700 & -2.9127700 & -2.395050 \\
\hline & -1 & -7.00000 & -2.092140 & -1.2682500 & -1.083490 \\
\hline & & & 0.040751 & & \\
\hline & 0 & 0.00656 & 0.943385 & 0.1395730 & 0.202822 \\
\hline \multirow[t]{3}{*}{1} & & 0.91861 & 1.673970 & 1.0165800 & 1.064510 \\
\hline & 2 & 1.65330 & 2.308470 & 1.7353500 & 1.775780 \\
\hline & 3 & 2.29033 & & 2.3624900 & 2.398190 \\
\hline \multirow[t]{7}{*}{0} & -3 & 5.60000 & 6.370750 & 9.8043300 & 14.151700 \\
\hline & -2 & -7.00000 & -6.072530 & -4.2039000 & -3.382520 \\
\hline & -1 & 0.00000 & 0.102859 & 0.3835770 & 0.551618 \\
\hline & 0 & 1.89540 & 1.944410 & 2.0856300 & 2.175420 \\
\hline & 1 & 3.07225 & 3.105680 & 3.2037600 & 3.267420 \\
\hline & 2 & 3.97151 & 3.997770 & 4.0754200 & 4.126280 \\
\hline & 3 & 4.72129 & 4.743410 & 4.8090800 & 4.852300 \\
\hline \multirow[t]{7}{*}{1} & -3 & 5.45375 & 5.382340 & 5.2727200 & 5.235480 \\
\hline & -2 & 6.36693 & 6.308060 & 6.2181600 & 6.187750 \\
\hline & -1 & 7.15291 & 7.102520 & 7.0258500 & 7.000000 \\
\hline & 0 & 7.84792 & 7.803620 & 7.7363900 & 7.713760 \\
\hline & 1 & 8.47470 & 8.434960 & 8.3747700 & 8.354550 \\
\hline & 2 & 9.04836 & 9.012170 & 8.9574400 & 8.939070 \\
\hline & 3 & 9.57943 & 9.546080 & 9.4957000 & 9.478800 \\
\hline \multirow[t]{7}{*}{1.5} & -3 & 9.33501 & 9.356620 & 9.4209300 & 9.463390 \\
\hline & -2 & 9.94000 & 9.959680 & 10.0183000 & 10.057100 \\
\hline & -1 & 10.50000 & 10.518100 & 10.5721000 & 10.607900 \\
\hline & 0 & 11.02270 & 11.039500 & 11.0897000 & 11.122900 \\
\hline & 1 & 11.51380 & 11.529500 & 11.5765000 & 11.607600 \\
\hline & 2 & 11.97800 & 11.992800 & 12.0370000 & 12.066400 \\
\hline & 3 & 12.41880 & 12.432800 & 12.4747000 & 12.502500 \\
\hline
\end{tabular}

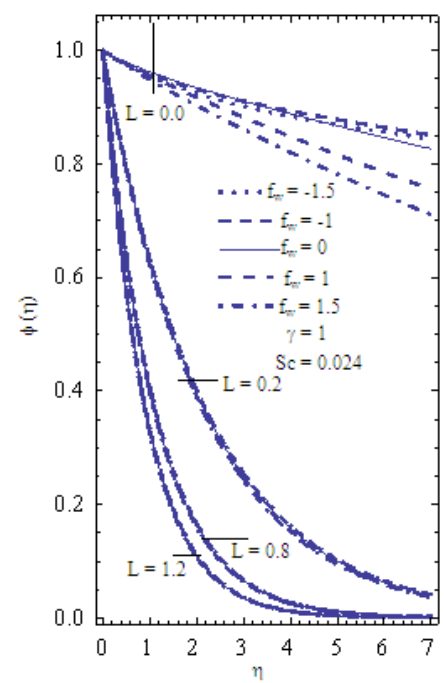

Fig. 2: Concentration profiles for various values of chemical reaction parameter $\mathrm{L}$ and mass transfer $f_{w}$ 


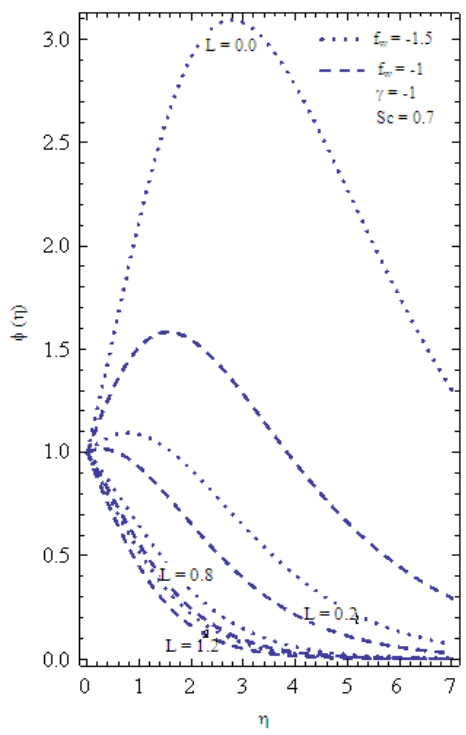

Fig. 3: Concentration profiles for various values of chemical reaction parameter $\mathrm{L}$ and injection $\mathrm{f}_{\mathrm{w}}<0$

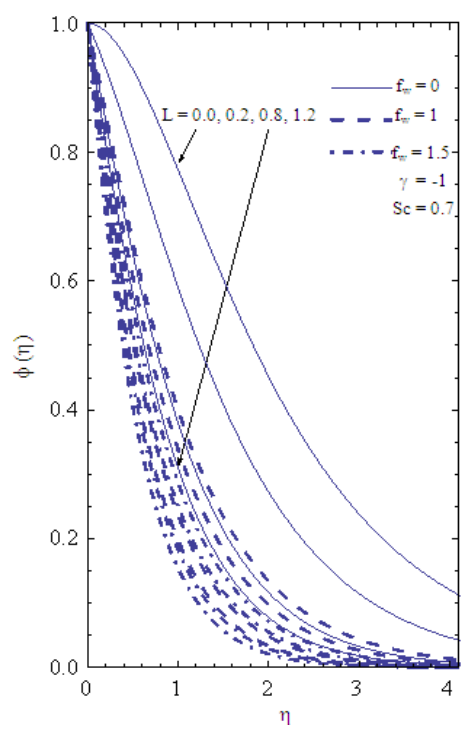

Fig. 4: Concentration profiles for various values of chemical reaction parameter $L$ and suction $f_{w}>0$

\section{DISCUSSION}

Now, we discuss the result. Figure 1 and 2 show the concentration profiles with Schmidt number $(\mathrm{Sc}=0.024)$ and concentration parameter $\gamma=-1,+1$ respectively. A pack of curves for each chemical reaction parameter $\mathrm{L}$ with different values of mass transfer $\mathrm{f}_{\mathrm{w}}$. For Schmidt number $(\mathrm{Sc}=0.024)$ and concentration parameter $\gamma=-1,+1$.

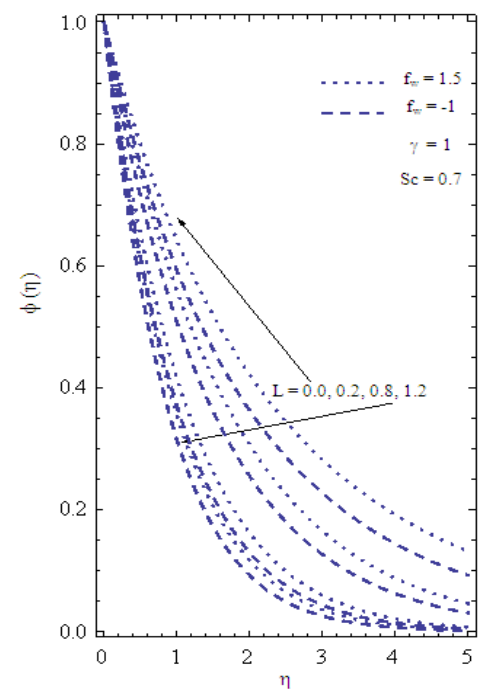

Fig. 5: Concentration profiles for various values of chemical reaction parameter $\mathrm{L}$ and injection $\mathrm{f}_{\mathrm{w}}<0$

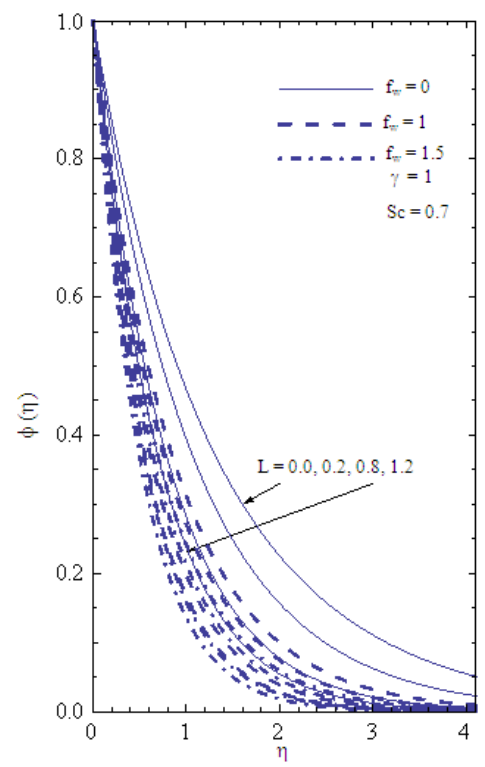

Fig. 6: Concentration profiles for various values of chemical reaction parameter $\mathrm{L}$ and suction $\mathrm{f}_{\mathrm{w}}>0$

Figure 1 and 2 shows the effects of the chemical reaction parameter $\mathrm{L}$ on the concentration profiles at various values of mass transfer parameter $f_{w}$. We observe that $\mathrm{L}$ reduce the concentration for each mass transfer parameter $f_{w}$. Also, the concentration decay to zero faster with $\mathrm{L}$ increases for each mass transfer parameter $f_{w}$. The suction parameter $\left(f_{w} \geq 0\right)$ reduces the concentration for each chemical reaction parameter 
J. Math. \& Stat., 5 (3):159-166, 2009

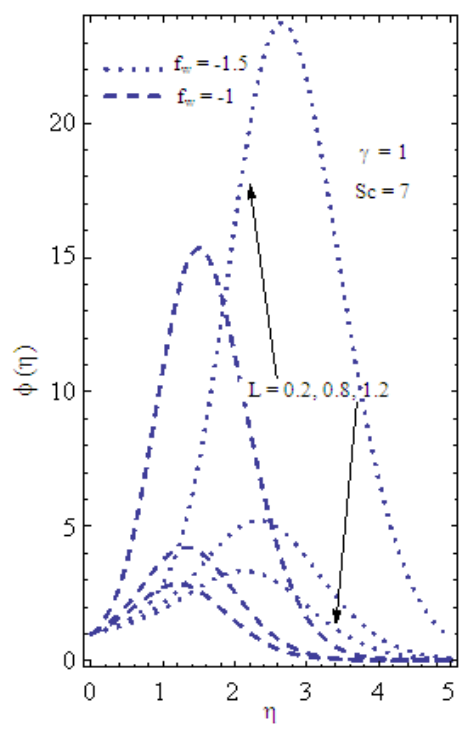

Fig. 7: Concentration profiles for various values of chemical reaction parameter $\mathrm{L}$ and injection $\mathrm{f}_{\mathrm{w}}<0$

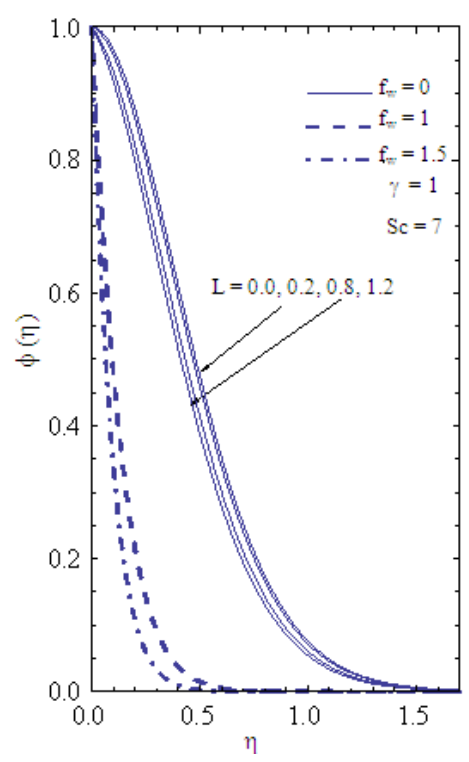

Fig. 8: Concentration profiles for various values of chemical reaction parameter $\mathrm{L}$ and suction $\mathrm{f}_{\mathrm{w}}>0$

with increases mass transfer parameter $f_{w}$ whereas the injection parameter $\left(f_{w} \geq 0\right)$ has the opposite effect except the case of injection with $\gamma=1$ and $L=0$ the concentration decreases with increases mass transfer parameter $f_{w}$ until a certain point for each injection parameter $\left(f_{w}<0\right)$ reverses the order of pack curves with large $\eta$.

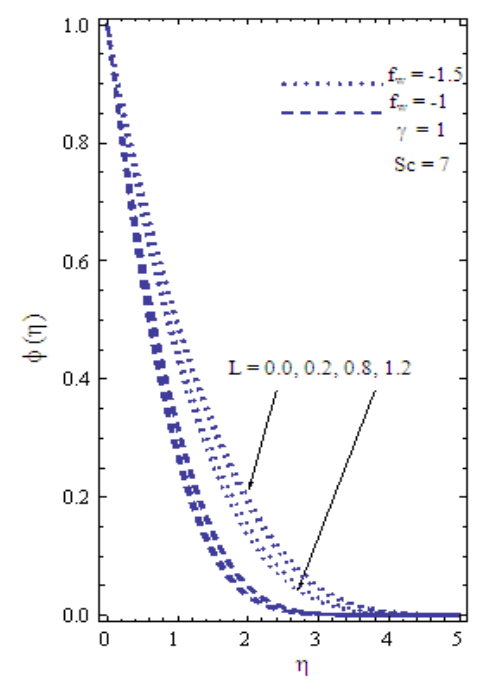

Fig. 9: Concentration profiles for various values of chemical reaction parameter $\mathrm{L}$ and injection $\mathrm{f}_{\mathrm{w}}<0$

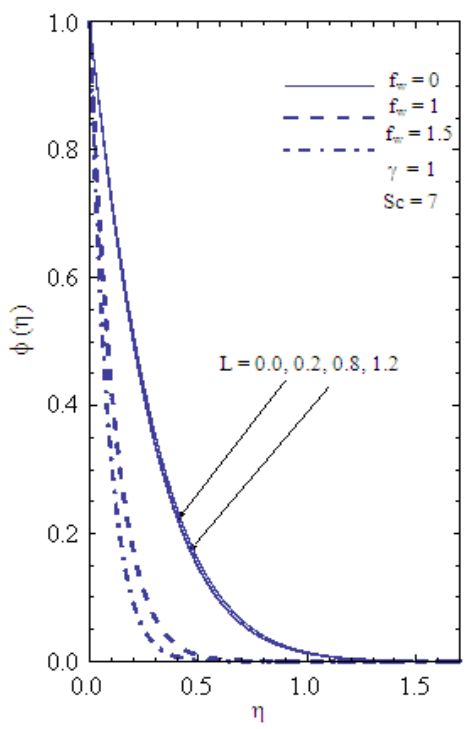

Fig. 10: Concentration profiles for various values of chemical reaction parameter $\mathrm{L}$ and suction $\mathrm{f}_{\mathrm{w}}>0$

Figures 3 and 4 show the concentration profiles with Schmidt number $(\mathrm{Sc}=0.7)$ with concentration parameter $\gamma=-1$. Figure 3 shows the effects of the chemical reaction parameter $\mathrm{L}$ on the concentration profiles at various value of injection parameter $f_{w}$. In Fig. 3, we observe that $\mathrm{L}$ reduce the concentration for each injection parameter $\left(f_{w}<0\right)$. Also, for $L=0$, the concentration profiles reaches a maximum and then 
decay to zero. Increasing values of the injection parameter move the location of the maximum value of the concentration profiles away from the surface. For $\mathrm{L} \neq 0$ there exist two cases, the first case for small $\mathrm{L} \in(0, \mathrm{Lc})$, the concentration profiles has a point of inflection for each $\left(f_{w}<0\right)$. While, Fig. 4, we observe that $\mathrm{L}$ reduce the concentration for each suction parameter $\left(f_{w} \geq 0\right)$. The increases in suction reduces the concentration for each $\mathrm{L}$.

Figure 5 and 6 show the concentration profiles with Schmidt number for gases $(\mathrm{Sc}=0.7)$, with concentration parameter $\gamma=1$. Figure 5 and 6 shows the effects of the chemical reaction parameter $\mathrm{L}$ on the concentration profiles at various value of mass transfer parameter $f_{w}$. We observe that $L$ reduce the concentration for each mass transfer parameter $\mathrm{f}_{\mathrm{w}}$.

For $(\mathrm{Sc}=7)$, with concentration parameter $\gamma= \pm 1$, Figure 7 and 10 shows the effects of the chemical reaction parameter $L$ on the concentration profiles at various value of mass transfer parameter $f_{w}$. In Fig. 7, we observe that $\mathrm{L}$ reduce the concentration for each injection parameter $\left(f_{w}<0\right)$. Whereas the concentration increases with increasing the injection parameter. The concentration profiles reaches a maximum and then decay to zero. Increasing values of the injection parameter move the location of the maximum value of the concentration profiles away from the surface whereas the increasing values of chemical reaction parameter $\mathrm{L}$ move the location of the maximum value of the concentration profiles near from the surface. While in Fig. 8 and 10, the curves represent a pack for each mass transfer parameter $f_{w}$ with different values of chemical reaction parameter L. Also, for each mass transfer parameter $f_{w}$ the concentration decreases with increasing the chemical reaction parameter $\mathrm{L}$.

\section{CONCLUSION}

In this study we study the effects of suction/ injection and chemical reaction on mass transfer over a stretching surface. The presence of suction and injection serves to introduce one extra parameter into the problem, namely $f_{w}$. The effects of chemical reaction introduce a parameter L. Also, Schmidt number Sc and concentration parameter $\gamma$. We find an analytical exact solution for the boundary value problems. We discuss the exact solution for different values of parameters.

\section{REFERENCES}

1. Griffith, R.M., 1964. Velocity temperature and concentration distributions during fiber spinning. Ind. Eng. Chem. Fundamental, 3: 245-250. DOI: 10.1021/i/60011a013
2. Erikson, L.E., L.T. Fan and V.G. Fox, 1966. Heat and mass transfer on a moving continuous moving flat plate with suction or injection. Ind. Eng. Chem. Fundam., 5: 19-25. DOI: 10.1021/i160017a004

3. Chin, D.T., 1975. Mass transfer to a continuous moving sheet electrode. J. Electrochem. Soc., 122: 643-646.

http://scitation.aip.org/getabs/servlet/GetabsServlet ?prog=normal\&id=JESOAN000122000005000643 000001\&idtype $=$ cvips \& gifs $=$ yes

4. Gorla, R.S.R., 1978. Unsteady mass transfer in the boundary layer on a continuous moving sheet electrode. J. Electrochem. Soc., 125: 865-869. http://scitation.aip.org/getabs/servlet/GetabsServlet ?prog=normal\&id=JESOAN000125000006000865 $000001 \&$ idtype $=$ cvips $\&$ gifs $=$ yes

5. Das, U.N., R.K. Deka and V.M. Soundalgekar, 1994. Effects of mass transfer on flow past an impulsively started infinite vertical plate with constant heat flux and chemical reaction. Forsch. Ingenieurwes, 60: 284-287. DOI: 10.1007/BF02601318

6. Anderson, H.I., O.R. Hansen and B. Holmedal, 1994. Diffusion of a chemically reactive species from stretching sheet. Int. J. Heat Mass Trans., 37: 659-664.

http://cat.inist.fr/?aModele=afficheN\&cpsidt $=4035303$

7. Anjalidevi, S.P. and R. Kandasamy, 1999. Effects of a chemical reaction heat and mass transfer on laminar flow along a semi infinite horizontal plate. Heat Mass Trans., 35: 465-467. DOI: 10.1007/s002310050349

8. Anjalidevi, S.P. and R. Kandasamy, 2000. Effects of a chemical reaction heat and mass transfer on MHD flow past a semi infinite plate. Z. Angew. Math. Mech., 80: 697-701. http://cat.inist.fr/?aModele $=$ afficheN\&cpsidt $=1520$ 455

9. Muthucumaraswamy, R. and P. Ganesan, 2000. On impulsive motion of a vertical plate with heat flux and diffusion of chemical reactive species. Forsch. Ingenieurwe., $\quad 66$ : 17-23. DOI: $10.1007 / \mathrm{s} 100100000026$

10. Muthucumaraswamy, R. and P. Ganesan, 2001. First-order chemical reaction on flow past an impulsively started vertical plate with uniform heat and mass flux. Acta Mech., 147: 45. DOI: 10.2007/s00707-006

11. Muthucumaraswamy, R., 2002. Effects of suction on heat and mass transfer along a moving vertical surface in the presence of a chemical reaction. Forsch. Ingenieurwe., 67: 129-132. DOI: 10.1007/s10010-002-00832 
12. Bird, B.R., W.E. Stewart and E.N. Lightfoot, 2002. Transport Phenomena. John Wiley and Sons, New York, USA., ISBN: 0-471-41077-2, pp: 164.

13. Gupta, P.S. and A.S. Gupta, 1977. Heat and mass transfer on a stretching sheet with suction or blowing. Can. J. Chem. Eng., 55: 744-746. DOI: $10.1002 /$ cjce. 5450550619

14. Andersson, H.I., 1995. An exact solution of the Navier-Stokes equation for magnetohydrodynamic flow. Acta Mechanica, 113: 241-244. DOI: 10.1007/BF01212646
15 Cortell, R., 2005. Flow and heat transfer of a fluid through a porous medium over a stretching surface with internal heat generation/absorption and suction/blowing. Fluid Dyn. Res., 37: 231-245. http://www.iop.org/EJ/abstract/1873-

7005/37/4/A02 